\title{
A Roadmap to Increase Active Learning: Reading Methodology Courses with Problem-Based Learning in Professional Learning Communities
}

\author{
Stephanie S. TeKippe \\ Wartburg College
}

Active learning engages students and prompts them to think critically, work collaboratively, express ideas, explore knowledge, make connections, and reflect. Problem-based learning (PBL) is an active learning strategy commonly utilized in STEM courses. The author of this study explored the use of PBLs in a reading methodology course. The findings revealed increased student retention of knowledge when using PBLs in Professional Learning Communities, compared to traditional formats. Student recall and perceptions were examined in a collaborative environment, therefore providing a roadmap of integration, increased participation, and student success.

\section{INTRODUCTION}

School administrators, educators, and college professors of pre-service teachers recognize the benefits derived from active learning. While active learning successes have been documented as far back as the 1800 s with Dewey and Vgotsky, there is a disconnect between understanding the impact on student learning and implementing active learning strategies in the practice of teaching. Lecture as an instructional strategy continues to dominate college courses (Michael, 2007). However, by design, lectures are teacher-focused, and they often are ineffective (Freeman et al., 2014) and tedious. In addition, reliance on lectures as the primary form of instruction constitutes a missed opportunity for education faculty to model active learning for pre-service teachers.

Even pre-service teachers with the best intentions often revert to what they know and have experienced as learners. Four years of college education, dominated by lectures, do not offer them the opportunity to observe active learning in action or experience learner-centered teaching strategies from a student perspective. A teacher's main focus is to foster an environment where students grow and learn. Active learning is a teaching method designed to deepen critical reflection (Raelin \& Coghlan, 2006) and student engagement (Ryan \& Deci, 2000). Central to active learning methods is an increase in student achievement (Araz \& Sungur, 2007). Reading methodology courses that implement active learning can better prepare future teachers for their careers with an increased emphasis on accountability of student learning and achievement. In addition to modeling what administrators expect pre-service teachers to execute, actively engaging students in the learning process increases: student retention of content (Lord, 2007), motivation (Ryan \& Deci, 2000), and implementation of active learning (Pepper, Blackwell, Monroe, \& Coskey, 2012).

The purpose of the study described here was to explore the effects of active learning strategies with pre-service teachers and discover an effective implementation framework of active learning, including problem-based learning (PBL), in a reading methodology course. Students should engage in active 
learning throughout all methodology courses. While PBLs are common in science and math courses, more research is needed in using PBLs for reading methodology courses. Active learning engages students and results in increased retention of knowledge. Pre-service teachers who retain knowledge are more prepared for future responsibilities. Furthermore, well-prepared teachers are more likely to remain in the profession and produce higher achieving students (NCATE, 2010). Including active learning in reading methodology courses will increase student achievement, student engagement, and, therefore, better prepare pre-service teachers to teach reading.

Teacher education faculty must assume the responsibility of providing opportunities for pre-service teachers to practice active learning as students. Experiencing active learning as pre-service teachers, while faculty model the learning strategy, is critical as pre-service teachers will be expected to implement this teaching method (Pepper, Blackwell, Monroe, \& Coskey, 2012). Including active learning in pre-service teaching methodology courses is not as simple as merely deciding to facilitate a student-centered classroom. An important consideration for professors is how to implement or demonstrate active learning effectively to increase the probability of an active learning presence in future teachers' classrooms.

Active learning has multiple definitions and a plethora of strategies. For purposes of the research described here, active learning was operationally defined as students actively "doing" versus merely listening, which results in processes of constructing knowledge, testing, and modifying knowledge constructs. Furthermore, while there are many active learning practices, this study focused on two commonly applied strategies: cooperative learning and problem-centered learning (Pepper, Blackwell, Monroe, \& Coskey, 2012).

The study spanned three years. During that time, the researcher explored the effectiveness and implementation of active learning in a reading methodology course. The experiences included both failures and successes, resulting in a roadmap to integrate effective active learning through collaboration and problem-based learning in a reading methodology course.

\section{READING METHODOLOGY COURSE}

The course description for the third-year reading methodology course that served as the setting for this study states that the course focuses on the "...development and application of skills and strategies to assist elementary students in reading, comprehension, interpreting, evaluating, and appreciating texts." The course includes discipline-specific preparation in literacy education. The reading instruction features balanced literacy as a program, lesson development, and field experiences.

Consequently, a balanced literacy approach is utilized to guide pre-service teachers in the practice of teaching reading. Balanced literacy is a method of integrating multiple literacy instruction modalities, which include explicit instruction and authentic texts (Sadlier, 2015). Balanced literacy offers elementary students opportunities to actively participate and engage with authentic texts, while becoming proficient and skilled in both reading and writing. Across classrooms in America, balanced literacy is a prominent practice, which receives attention from literacy advocates, such as Lucy Calkins, Iren Fountas, and Gay Sue Pinnell (Goltche, 2016).

Alongside balanced literacy, the revised Bloom's Taxonomy and Webb's Depth of Knowledge (DOK) are applied to develop, teach, and assess reading lessons. The revised Bloom's Taxonomy promotes completion of tasks and student understanding (Anderson, Krathwohl, David, \& Bloom, 2001), while DOK accelerates higher-order thinking processes and increases rigor (Hess, 2013).

The course has a co-requisite field experience for 15 hours of practice in an elementary reading classroom. Pre-service teachers develop, teach, assess, and reflect on lessons. Throughout the semester, 12 lessons are developed, which include components of balanced literacy (e.g., shared reading, guided reading), coupled with the foundations of literacy (e.g., comprehension, vocabulary, fluency). 


\section{ACTIVE LEARNING IN METHODOLOGY COURSES}

Active learning moves from teacher-centered rote memorization to student-centered learning that engages students in a purposeful manner (Edwards, 2015), utilizing real-life experiences to construct knowledge (Mascolo \& Fishcer, 2005). In student-centered environments, learners are active participants, compared to lectures where students passively observe (Olgun, 2009). Methodology courses that utilize active learning, with problem-based learning as a strategy, provide students a platform to develop knowledge in key concepts within a learning group (Oliveira, Wilcox, Applebee, Amodeo, \& Snyder, 2013). Professors have the freedom to implement active learning models versus simply lecturing on the definition and reasoning of active learning. When taught in a traditional lecture-based class without effective modeling, future teachers are less likely to implement active learning (Arce, Bodner, \& Hutchingson, 2014). In addition to modeling a strategy, methodology professors also can increase student engagement (Edwards, 2015) and motivation (Ryan \& Deci, 2000), while increasing recall of knowledge (Lord, 2007). Both pre-service teachers and methodology professors benefit from implementation.

It is important to note that not all active learning strategies yield the same desired results when considering increased learning outcomes and transfer of knowledge to the workforce. Davis and Summers (2014) described the highest increase in recall and transferability of knowledge to the workforce with concrete activities where students are doing or engaging in real-life experiences $(70 \%$ to $90 \%$ recall). Moderate learner recall occurs when students observe or are shown the experience (30\% to $50 \%$ recall); the lowest learner recall occurs with abstract activities where students are told through reading or hearing ( $10 \%$ to $20 \%$ recall). The two highest levels of recall result from hands-on workshops or collaboration and simulations that model a real experience or doing the real thing, for example, teaching (Davis \& Summers). Other researchers have had similar results with increased learner retention and transfer of knowledge when engaging students in concrete versus abstract activities (Hamilton \& Tee, 2016; Lord, 2007).

Active learning was implemented in the researcher's reading methodology course, followed by an exploration of learner recall and student perceptions at the end of the semester. Active learning strategies included, but were not limited to, problem-based learning, project-based learning, collaborative PBL work in professional learning communities, and teaching.

\section{PROBLEM-BASED LEARNING}

Problem-based learning is a conceptual model often used in STEM fields. PBLs can be described as "using real world situations (problems), group learning, student-directed solutions for problems, and teacher serving as facilitators of learning" (Downing, 2013, p. 621). With the foundation of PBLs in medical education (Freer, 2017), few studies, if any, incorporate PBL usage in reading methodology courses. However, PBLs encompass the essence of literacy through reading, writing, listening, and speaking. "Problem-Based Learning is thus an approach to learning that is characterized by flexibility and diversity in the sense that it can be implemented in a variety of ways in and across different subjects and disciplines in diverse contexts" (Savin-Baden, 2000, p. 3).

Problem-based learning is based on the ideals of a constructivist approach (Freer, 2017) that affords students the opportunity to collaborate, discover, construct knowledge, and learn procedural steps to solve problems. The scenarios are based in real-world issues, therefore increasing relevance to students, while the professor acts as a facilitator. In this research, the following four problems were presented to students: Unpacking the Literacy Core, Early Literacy Intervention: Summer Reading Program, Reading Interventions and Strategies, and Professional Development Workshop for a Balanced Approach Literacy Program. Each PBL took approximately two weeks to work through the process of clarifying, defining the problem, analyzing, re-structuring the problem, formulating learning goals, learning independently, reporting back to the group, presenting and supporting the solution. Students typically received two hours of class time to work in collaborative groups, with the remaining time spent outside of class. The first year, students were allowed to choose different PBL groups for each problem, while the second-year 
students were placed in the same collaborative group for the entire semester. The third year, students chose a collaborative group for the length of the term, formed by endorsement or specialty areas, using a professional learning community model.

\section{PROFESSIONAL LEARNING COMMUNITIES}

In the third year of this study, pre-service teachers were grouped into professional learning communities (PLC). The education profession has been criticized for teachers practicing in isolation, resulting in a renewed emphasis on collaborating with colleagues (Council of Chief State School Officers, 2011). Practicing teachers in the field engage in PLCs to increase student achievement (Hall \& Hord, 2011) through systematic-collaborative work, which increases teacher ownership and motivation (Leithwood \& Louis, 2012), with the goal of continuous improvement (DuFour \& Marzano, 2011). A key element to PLCs is the use of data and research to make informed decisions (Saleh \& Khine, 2012) about curriculum and student growth (Vescio, Ross, \& Adams, 2008).

Action research is a method for instructors to engage in data collection and research. In educational settings, action research is a cyclical study of student learning and instructional strategies used improve the practice of teaching and therefore, improve student learning (Lesha, 2014). Action research is a formative discovery of student learning with a purpose of solving problems "in action" (Lesha, 2014). PLCs are a structured and collaborative environment where educators can engage in action research.

Similar to the need for modeling active learning, teacher programs must provide opportunities for students to experience PLCs. PLCs have a positive effect on the practice of teaching, in addition to student learning (Vescio, Ross, \& Adams). The implementation of PLCS in the reading methodology course was twofold. First, PLCs engaged students in an organized process to complete PBLs successfully. Second, PLCs afforded students experience in a common practice within the field of education, while improving pre-service teachers' instructional practice.

\section{RESEARCH METHOD AND DESIGN}

Data were collected from pre-service teachers in a 15-week reading methodology course. Participants were in their third year at a private liberal arts college. Three different groups, one group each year, of approximately 24 pre-service teachers participated over the span of three years. The cross-sectional study was qualitative and featured the use of triangulated data. The theoretical framework consisted of a constructivist approach. The "constructivist approach involves reconstructing knowledge, rather than accepting a piece of information as a given" (Semerci \& Batdi, 2015, p. 172). Students are active in the construction of knowledge through connecting current and past knowledge (Jonassen, 1991). Using a constructivist approach, students move beyond the traditional format of receiving information through hearing and reading into actively transmuting information by developing hypothesis, engaging in decision making, and accessing cognitive schemas (Kearsley \& Culatta, 2016). The research took place in the Midwest at a private, four-year, residential college. Data were collected using: open-ended surveys, informal interviews, assignments, and student end-of-course evaluations. Analysis of qualitative data revealed common themes and patterns, with three broad steps of data analysis including: organizing data into text, organizing and reducing textual data into themes, and illustrating the coded data (Creswell, 2007).

\section{COURSE EVOLUTION}

\section{Course Objectives and Task}

Student learning outcomes in the reading methodology course were accomplished using five different methods to achieve each objective, including: reading from textbook and a subsequent reading quiz, short lecture (10-20 minutes/ 10-20\%) and class discussion, field experience, including lesson plan development and teaching, PBLs, and in the third year, PLC work encompassing a book study, research, 
and PBL or project-based learning. The PLC was introduced in the third year of the research project. The purpose of presenting the objectives in five different manners was to explore which method was most effective helping learners retain information and which was perceived as effective or ineffective at the end of the course by students. Upon completion of coursework in years two and three, students were asked to write one paragraph for each objective to describe how they learned the objective and a summary of what was learned. Students were also tasked with submitting a detailed recollection of the most beneficial elements or methods of the course and describing components that were not considered valuable to learning the content or future application within the field of teaching.

\section{Active Learning in a Reading Methodology Course}

The first year active learning was incorporated but these attempts lacked purpose or structure. Upon reflection, active learning activities were randomly sprinkled into a lecture-based course. The instructor was aware of the student benefits from active learning but lacked a system to effectively integrate active learning aligned with the learning objectives. Furthermore, the benefits and purposes of active learning were not communicated to students.

The second year, an attempt was made to be more purposeful with an emphasis on active learning and shift from teacher-centered to student-centered. Students worked in collaborative groups during PBL activities. Furthermore, the course instructor explained the purpose for including active learning, along with the benefits for student learning. While the second year was an improvement, the collaborative group work lacked structure.

The third year remained consistent, with a student-centered environment, the same learning objectives, and active learning strategies. However, in the third year, students were placed into PLC groups, based on endorsement areas, and met regularly after completing a PLC contract, which included a systematic process. Three practices were shifted into the PLC collaborative environment, including: research, PBLs, and a book study. The modification of including PLCs in the course while moving three activities within the new framework changed the course.

\section{RESULTS}

\section{Learner Recall of Course Objectives}

At the end of the reading methodology course in year two and three, students were instructed to write one paragraph, per objective, including: how the student learned each course objective and what was learned for each objective. The methods to teach each course objective included independent reading followed by a reading quiz, a whole-class lecture with small group or whole group discussion, experiential learning (teaching elementary reading to K-6 students), problem-based learning, and collaborative work using the PLC model (added Year 3), which was comprised of a book study, research, and PBLs. Prior to year three, students engaged in a book study and research independently.

In the second year, $87 \%$ of the responses attributed active learning methods to learning the course objectives. The top four strategies, expressed by participants, for retention of learning objectives were developing lesson plans and teaching (24\%), developing a unit (20\%), working in PBL groups (18\%), and discussions (14\%) (See Figure 1). Passive learning components of lecture, reading, and quizzes resulted in $13 \%$ of student responses on how objectives were learned. Students learned and retained knowledge from active learning at $87 \%$, compared to passive learning at $13 \%$. An argument could be made that quizzes do not belong in the category of passive learning. However, even though students were applying information gained from reading the textbook when taking the quiz, the main component of the activity was reading. The quizzes were short, consisting of five to eight multiple choice questions. The goal of including reading quizzes was to ensure students were, in fact, reading. After students read and formed a knowledge base, a short lecture and discussion followed. The lecture and discussion were kept to 10 to $20 \%$ of the class time, which equaled no more than 20 minutes. After the discussion, the focus shifted to building and constructing knowledge in active learning environments. 
FIGURE 1

2015 STUDENT RECALL ON LEARNING OUTCOMES

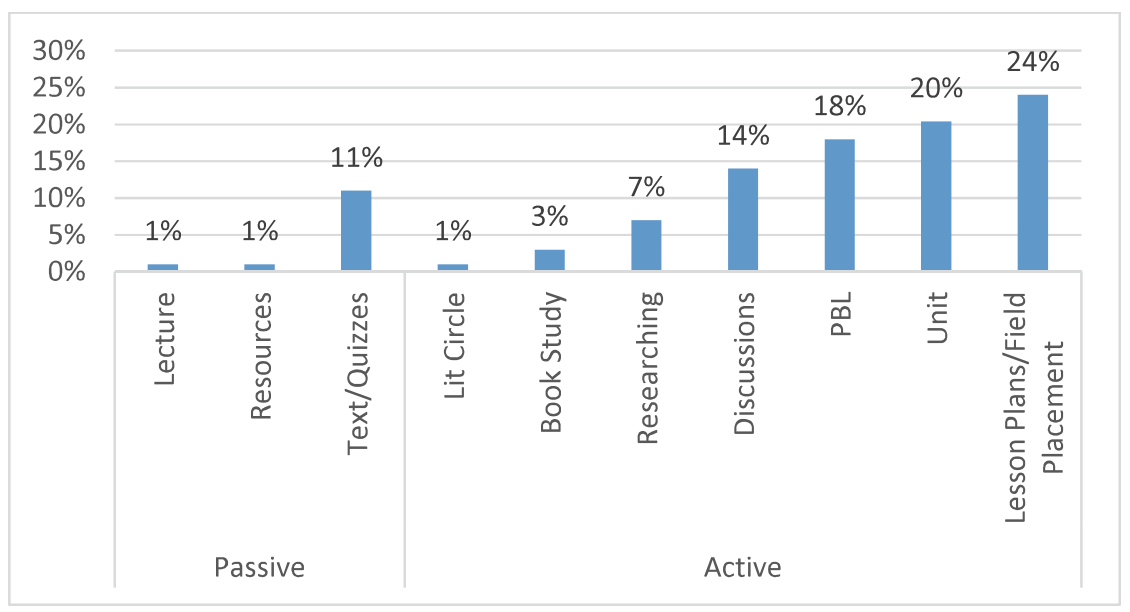

Similar to the second year, in year three, $88 \%$ of the responses attributed active learning methods to learning the course objectives (See Figure 2). The top four active learning activities for retention of learning objectives were developing lesson plans and teaching $(36 \%)$; PLCs including PBLs, book studies, and research $(29 \%)$; discussions $(12 \%)$; and developing a balanced literacy unit $(10 \%)$. Within PLCs, research garnered $11 \%$ of the $29 \%$. The passive learning components of lecture, reading, and quizzes equaled $12 \%$ of student responses on how objectives were learned, with the text and quizzes scoring higher than developing a unit.

FIGURE 2

\section{STUDENT RECALL ON LEARNING OUTCOMES}

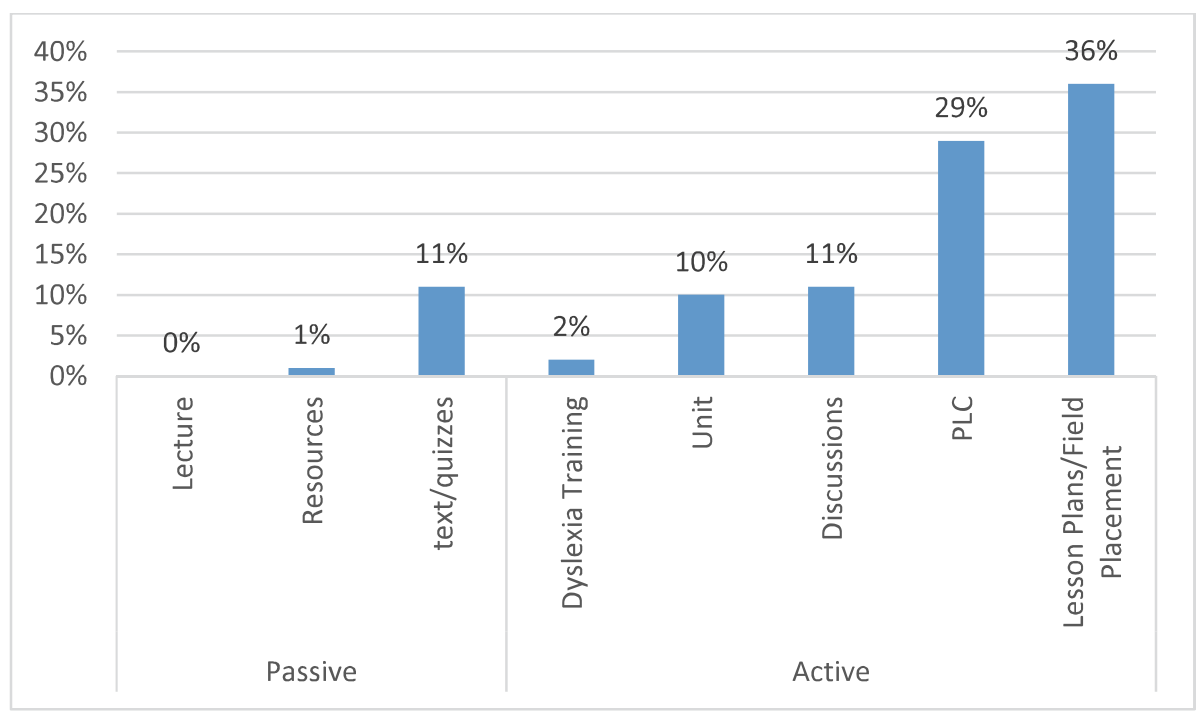

The percentages for active learning versus passive learning in years two and three remained similar at $87 \%$ (year two) and $88 \%$ (year three). Passive learning also remained consistent with $13 \%$ (year two) and $12 \%$ (year three). Reading the textbook and quizzes was the highest percentage of responses for passive learning with $11 \%$ both years. Changes occurred between year two and three in the top four active learning strategies. While developing lesson plans and teaching remained at the top, developing a unit 
dropped from second in year two to fourth in year three. Working in PBLs was third in year two with $18 \%$. In year three, PLCs, which included PBLs increased to $29 \%$. Out of the $29 \%$, research accounted for $11 \%$ with the remaining $18 \%$ for PBLs as the book study did not receive any student responses for recall. Developing a unit dropped from $20 \%$ in year two to $10 \%$ in year three.

\section{Student Perceptions of Most Effective Learning Opportunities}

Students were also asked to describe learning opportunities perceived to be most effective in learning the course objectives. The results follow.

In year two, $45 \%$ percent of students perceived field experiences to be the most effective learning opportunity, followed by development of the reading unit $(21 \%)$ and open discussions $(11 \%)$. In year three, $57 \%$ of students perceived PLCs to be the most effective method to learn, followed by field experiences $(21 \%)$ and open discussions $(21 \%)$.

In both years, field experience results for most effective strategies were consistent with student recall of how objectives were learned. Although in year two, PBLs were in the top three strategies of student recall from learning, PBLs were absent from participant responses of effective strategies. In year three, PBLs were included in both the recall and effective strategy categories. While research was absent from the top three recall of strategies and effective strategies, in year two, research was in the top three for recall and effective sets in the third year.

\section{Student Perceptions of Least Effective Learning Opportunities}

Students were also instructed at the end of the semester to write what they perceived as the least effective learning opportunity for growth and retention of knowledge. The second year, students found the lecture and materials related to phonics the least effective $(40 \%)$, followed by PBLs $(30 \%)$ and research articles (10\%). In year two, students in the third year found the phonics component the least effective $(57 \%)$, followed by quizzes $(29 \%)$ and literature circles $(14 \%)$.

In both the second and third years, the phonics instruction was labeled ineffective. PBLs and research were also included in student perceptions of least effective methods to learn course objectives in year two. However, in year three, PBLs and research were not listed by any of the participants as ineffective strategies. Quizzes and literature circles replaced PBLs and research for least effective learning opportunities in year three.

\section{Student End-Of-Course Evaluations}

End-of-course evaluations were completed by students and reviewed in the areas of "Stimulated Interest", "Encouraged Participation", and "Quality of Teaching" (Table 1). Students responded to the end-of-course evaluations in the following categories on a scale of one to five, with one indicating "Not at All", three representing "Somewhat", and five indicating "Very". In year three, the mean increased in "Stimulated Interest" and "Quality of Teaching." The mean for encouraging participation remained the same. The largest increase was in the quality of teaching moving from a 4.5 in the second year to a 4.95 in the third year.

TABLE 1

STUDENT END-OF-COURSE EVALUATIONS

\begin{tabular}{|r|r|r|r|r|}
\hline & \multicolumn{2}{|c|}{ Year 2 } & \multicolumn{2}{c|}{ Year 3 } \\
\hline & Mean & SD & Mean & SD \\
\hline Stimulated Interest & 4.6 & .45 & 4.85 & .35 \\
\hline Encouraged Participation & 4.9 & .2 & 4.9 & .3 \\
\hline Quality of Teaching Good & 4.5 & .6 & 4.95 & .15 \\
\hline
\end{tabular}




\section{A NEW FRAMEWORK FOR ACTIVE LEARNING IN READING METHODOLOGY COURSES}

Admittedly, the first year was a poor attempt at moving to a student-centered environment, as at least half, if not more, of the class was dedicated to a traditional format of lecture. In the second and third year, a concerted effort was made to engage students in active learning through collaborative work and PBLs.

Interesting and concerning connections formed from the second-year data. A disconnect evolved with PBLs ranking in the top three learning activities for retention of learning but was not regarded as an effective strategy by participants. PBLs ranked second in perceptions of least effective strategies. Another focal point was the low rankings, overall, for research. Student recall on learning outcomes for research scored a mere $7 \%$, in addition to inclusion on the list for least effective learning opportunities.

The field placement and lessons plans remained high on the list of promoting student recall of learning outcomes and most effective strategies. The reading unit and open discussions remained steady in the $10-11^{\text {th }}$ percentile, while also being included in effective learning opportunities.

Alarm was prevalent, as students regarded PBLs and research to be ineffective in the reading methodology course. While research is critical to making informed decisions in the education field (Saleh, \& Khine, 2012) and PBLs provide opportunities to engage in real-life experiences to increase learner recall (Davis \& Summers, 2014), the design of the course needed adjustments. The framework for the course was not conducive to students' experiencing and observing active learning strategies as effective, even if student recall occurred.

A new framework for the reading methodology course evolved from the first year to the third year. The goal was consistent with findings from current research to engage students in critical reflection (Raelin \& Coghlan) and experiential learning to increase student recall (Davis \& Summers, 2014), therefore increasing motivation (Ryan \& Deci, 2000), and achievement (Araz \& Sungur, 2007).

In year three, the course was organized around a reduced amount of lecture, with a concentration on PLC groups. PLCs were included to engage participants in collaborative work, similar to teachers in K-12 classrooms, to increase ownership and motivation (Leithwood \& Louis, 2012). PLC groups remained consistent in members and purpose, while systematically engaging students in learning through PBLs, research, and a book study. The previous three components of the course from year two moved from individual work and inconsistent configurations during class time to structured PLCs in year three. The field experience and lesson plans remained the same from year two. At the start of the third year, time was dedicated to explaining the purpose of PLCs, benefits of PLCs, use of PLCs in school districts, and individualizing the PLC process for each group.

Within a student-centered course and the PLC framework, in the third year, PBLs ranked higher in student perceptions of effective learning strategies than previous years. The number of responses including PBLs also increased, in year three, when students were asked to identify learning strategies for learner recall of information. This is critical for pre-service teachers; as current literature supports the importance of modeling active learning effectively for future implementation in their own classroom (Arce, Bodner, \& Hutchinson, 2014). Unlike the second year, PBLs were no longer included in the top three least effective strategies in the third year. Similar to PBLs, research, within the PLC framework, ranked higher for student recall of information and was no longer included in student perceptions of least effective strategies to learn objectives.

In the new framework, students recognized the active learning strategies of PBLs and research as effective in the new framework. Furthermore, results from the end-of-course evaluations regarding the faculty's quality of teaching and student interest improved with the new framework.

The changes executed in year three yielded results that support effective modeling and implementation of PLCs, PBLs, research, and field experiences. The framework for active learning in a reading methodology course is simple in design. A description and model of the framework follow.

The framework (See Figure 3) starts with the backbone of any course, student learning outcomes. Each learning outcome is taught using more than one active learning strategy, with at least one strategy falling in the highest percentage of learner recall, which includes: participating in collaborative work and doing, in this case teaching. While the focus is on active learning, passive learning is not omitted. A 
background and foundation are important for students to build upon as they construct knowledge. This task is often executed using the revised Bloom's Taxonomy. Passive learning is kept to a minimum, with reading done outside of class. Passive learning continues in the classroom with a reading quiz, short lecture, discussion, and review of materials. The goal is to keep this component at 15 to 20 minutes or less. The class then shifts into active learning strategies.

The majority of active learning is completed in PLC groups, to increase student engagement (Leithwood \& Louis, 2012) and learner recall of information (Davis \& Summers, 2014) through systematic collaborative work, which is consistent with the literature and findings from this research. The purpose and value of PLCs are explored early in the term, and PLC groups remain consistent throughout the course.

Each course objective is addressed using at least two active learning strategies with at least one of the strategies is to be completed in the PLC group. The course instructor also chooses at least one of the strategies from the highest level of learner recall and transferability to the workforce. The highest level of learner recall includes students doing or engaging in real-life experiences (Hamilton \& Tee, 2016) resulting in 70 to $90 \%$ learner recall (Davis \& Summers, 2014).

The final step is evaluating the effectiveness of instructional strategies, course design, and student learning in addition to exploring pre-service teacher perceptions through action research. The process of assessing, reflecting, evaluating, and adjusting a methodology course can better prepare pre-service teachers for the practice of teaching. The benefits of better preparing students, through this model, are applicable across disciplines.

\section{FIGURE 3}

\section{A ROADMAP TO INCREASE ACTIVE LEARNING IN READING METHODOLOGY COURSES USING PROFESSIONAL LEARNING COMMUNITIES.}

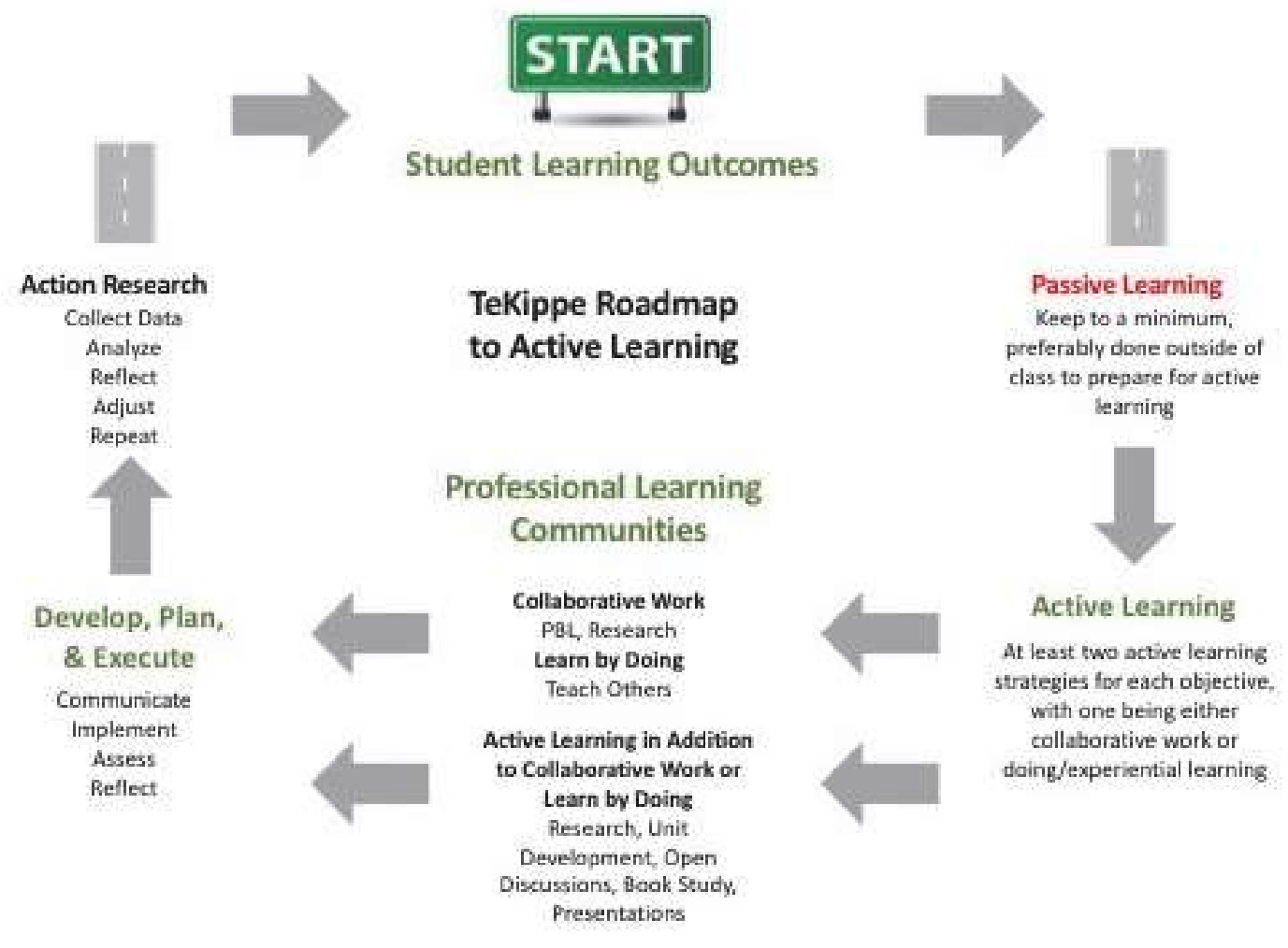




\section{CONCLUSION}

Simply modeling active learning does not necessarily equate to students appreciating or finding value in the learning strategy. Furthermore, a strategic framework for engaging students in active learning within a reading methodology course is central to success. When successfully engaging students in active learning within a methodology course, higher education as a field is better preparing educators to teach reading. In addition, all higher education fields benefit from increased student achievement, engagement, learner recall, and evaluations of faculty instruction.

The framework in higher education courses where active learning is modeled and experienced affects student perceptions on the value of active learning strategies. Perceptions play a significant role in preservice teachers choosing to implement active learning or going back to what they know, lecture.

The results of prior research and this study suggest that problem-based learning can serve as an effective active learning strategy for learners (Freer, 2017; Oliveira, Wilcox, Applebee, Amodeo, \& Snyder, 2013). Active learning can be implemented in higher education methodology courses, not only limited to STEM or, in this study, reading. If PBLs are incorporated into organized, collaborative learning environments, methodology courses are likely to yield positive results.

Not only did the PLC framework have an affirmative effect on a reading methodology course, PLCs are regularly practiced in the field of education. Professional learning communities are not specific to education or one field. The use of data and research in PLCs to make collaborative decisions to increase achievement (Saleh \& Khine, 2012) is applicable across higher education fields.

Learning from doing, or experiential learning, results in the highest level of learner recall of knowledge (Davis \& Summers, 2014). Students incorporated the elements from a balanced literacy program, with the main literacy elements using the revised Bloom's Taxonomy and Depth of Knowledge to develop lesson plans, teach, and reflect. Teaching others can result in $90 \%$ learner recall (Davis \& Summers). Similar to current research, in the second and third years of the study, lesson plan development and teaching resulted in learner recall in addition to student perceptions of this learning being an effective strategy. Learning by doing is imperative to the success of preparing future teachers. Implementing an experiential component across higher education fields yields similar results. Research and problem-solving also are important in higher education. Implementing a new framework resulted in a course design where learners retained knowledge and experienced the value of teaching, cooperative work, research, and using higher-order thought processes.

Shifting a methodology course from a teacher-centered classroom to a student-centered classroom requires thoughtful planning, preparation, execution, and evaluation of effectiveness, followed by modification of the course. Several years may be needed to find the right combination of active learning strategies in collaborative real-life experiences and higher-order thinking. The framework, or roadmap to increase active learning, has been effective with problem-based learning in professional learning communities. 


\section{REFERENCES}

Anderson, L.W., Krathwohl, D.R., \& Bloom, B.S. (2001). A taxonomy for learning, teaching, and assessing: A revision of Bloom's taxonomy of educational objectives (Complete ed.). New York: Longman.

Araz, G., \& Sungur, S. (2007). Effectiveness of problem-based learning on academic performance in genetics. Biochemistry and Molecular Biology Education, 35(6), 448-451.

Arce, J., Bodner, G.M., \& Hutchinson, K. (2014). A study of the impact of inquiry-based professional development experiences on the beliefs of intermediate science teachers about best practices for classroom teaching. International Journal of Education in Mathematics, Science and Technology, $2(2), 85-95$.

Council of Chief State School Officers. (2011). Interstate teacher assessment and support consortium (InTASC) model core teaching standards: A resource for state dialogue. Washington, D.C.: Council of Chief State School Officers.

Creswell, J.W. (2007). Qualitative inquiry and research method: Choosing among five approaches (2nd ed.). Thousand Oaks, CA: Sage.

Davis, B., \& Summers, M. (2014). Applying Dale's Cone of Experience to increase learning and retention: A study of student learning in a foundational leadership course. QScience Proceedings (Engineering Leaders Conference 2014) 2015:6 http://dx.doi.org/10.5339/qproc.2015.elc2014.6

Downing, K.E. (2013). Using problem-based learning to facilitate student learning. ACRL Proceedings (ACRL Conference 2013) 621-624.

DuFour, R., \& Marzano, R.J. (2011). Leaders of learning: How district, school, and classroom leaders improve student learning. Bloomington, IN: Solution Tree Press.

Edwards, S. (2015). Active learning in the middle grades. Middle School Journal, 46(5), 26-32.

Freeman, S., Eddy, S.L., McDonough, M., Smith, M.K., Okoroafor, N., Jord, H., \& Wenderoth, M.P. (2014). Active learning increases student performance in science, engineering, and mathematics. PNAS 111(23), 8410-8415.

Freer, P.K. (2017). Problem-based learning and structural redesign in methods courses. Contributions to Music Education, 42, 53-72.

Goltche, P. (2016). What is balanced literacy? My Learning Springboard. Retrieved from $\mathrm{http}: / /$ mylearningspringboard.com/what-is-balanced-literacy/

Hall, G.E., \& Hord, S.M. (2011). Implementing change: Patterns, principles, and potholes. (4th ed.) Upper Saddle River, NJ: Pearson Education, Inc.

Hamilton, J., \& Tee, S. (2016). The cone-of-learning: A visual comparison of learning systems. TQM Journal, 28(1), 21-39.

Hess, K. (2013). A guide for using Webb's depth of knowledge with common core state standards. The Common Core Institute. Retrieved from

https://education.ohio.gov/getattachment/Topics/Teaching/Educator-Evaluation-System/How-toDesign-and-Select-Quality-Assessments/Webbs-DOK-Flip-Chart.pdf.aspx

Jonassen, D. (1991). Evaluating constructivist learning. Educational Technology, 36(9), 28-33.

Kearsley, G., \& Culatta, R. (2016). Constructivist theory (J. Bruner). [Online]. Available: http://www.instructionaldesign.org/theories/constructivist.html [November 1, 2017].

Leithwood, K., \& Louis, K.S. (2012). Linking leadership to student learning. San Francisco, CA: Jossey-Bass Publishing.

Lesha, J. (2014). ACTION RESEARCH IN EDUCATION. European Scientific Journal, 10(13), European Scientific Journal, May 2014, Vol.10(13).

Lord, T. (2007). Revisiting the cone of learning: Is it a reliable way to link instruction method with knowledge recall? Journal of College Science Teaching, 37, 14-17.

Mascolo, M. \& Fischer, K. (2005). Constructivist theories. In Cambridge encyclopedia of child development, Eds. Hopkins, B., Barre, R. G., Michel, G. F., and Rochat, 49-63. Cambridge: Cambridge University Press. 
Michael, J. (2007). Faculty perceptions about barriers to active learning. College Teaching, 55(2), 42-47.

NCATE. (2010). Transforming teacher education through clinical practice: A national strategy to prepare effective teachers. Report of the Blue Ribbon Panel on Clinical Preparation and Partnerships for Improved Student Learning. Washington, D.C. www.ncate.org/ publications

Olgun, Ö. S. (2009). Engaging elementary preservice teachers with active learning teaching methodologies. The Teacher Educator, 44(2), 113-125.

Oliveira, A.W., Wilcox, K.C., Angelis, J., Applebee, A.N., Amodeo, V., \& Snyder, M.A. (2013). Best practice in middle-school science. Journal of Science Teacher Education, 24(2), 297-322.

Pepper, K., Blackwell, S., Monroe, A., \&Coskey, S. (2012). Transfer of active learning strategies from the teacher education classroom to prek-12 ${ }^{\text {th }}$ grade classrooms. Current Issues in Education, $15(3), 1-23$.

Raelin, J.A., \& Coghlan, D. (2006). Developing managers as learners and researchers: Using action learning and action research. Journal of Management Education, 30(5), 670-689.

Ryan, R.M., \& Deci, E.L. (2000). Intrinsic and extrinsic motivations: Classic definitions and new directions. Contemporary Educational Psychology 25, 54-67.

Sadlier, W.H. (2015). Core literacy: A K-5 resource for teachers of reading and language arts. Sadlier School. Retrieved from http://www.sadlier.com/school/core-literacy/overview-of-balancedliteracy-components-strategies

Saleh, I.M., \& Khine, M.S. (2012). Practitioner Research in Teacher Education Theory and Best Practices. Frankfurt: Lang, Peter, GmbH, Internationaler Verlag der Wissenschaften.

Savin-Baden, M. (2000) Problem-based learning in higher education: Untold stories. Buckingham: Open University Press.

Semerci, C. \& Batdi, V. (2015). A meta-analysis of constructivist learning approach on learners' academic achievements, retention, and attitudes. Journal of Education and Training Studies, 3(2), 171-180.

Vescio, V., Ross, D., \& Adams, A. (2008). A review of research on the impact of professional learning communities on teaching practice and student learning. Teaching and Teacher Education, 24, 8091. 